\title{
Visual Feeding by Juvenile Bear Lake Sculpin
}

\author{
DARCY NEVERMAN ${ }^{1}$ AND \\ WAYNE A. WurtsBaugh \\ Utah State University \\ Department of Fisheries and Wildlife \\ Ecology Center \\ Logan, Utah 8322-5210, USA
}

Abstract. - Young-of-the-year Bear Lake sculpin Cottus extensus feed throughout the day on benthic invertebrates and cease feeding at night when they migrate to the metalimnion. We investigated their reliance on vision by conducting feeding trials at different light levels in the laboratory. Feeding rate reached a maximum at intermediate light levels (near $10^{16}$ photons $\cdot \mathrm{m}^{-2} \cdot \mathrm{s}^{-1}$; approximately 1 lux) but decreased as light intensity increased beyond this range. At this maximum rate, the fish fed nine times faster than they were able to feed in the dark, showing that young Bear Lake sculpin rely heavily upon vision to feed. The light intensity at which feeding was greatest corresponded to intensities found on the bottom of Bear Lake (40-60 m) during the day.

Feeding and other behaviors differ greatly between the adults and juveniles of some fish species (Blaxter 1969; Emery 1973). Adult mottled sculpin Cottus bairdi can feed using mechanoreception or proprioception (Hoekstra and Janssen 1985); larvae of this species can also feed by nonvisual means (Jones and Janssen, in press). Young fish of many marine and freshwater fish species, however, are believed to feed visually (Blaxter 1966, 1974; Dabrowski 1982; Dabrowski and Jewson 1984). Our study was undertaken to determine if young-of-the-year (age-0) Bear Lake sculpin Cottus extensus rely on vision to feed and, if so, the light levels necessary for visual feeding to occur.

Bear Lake sculpin are endemic to Bear Lake on the Utah-Idaho border $\left(42^{\circ} \mathrm{N}, 111^{\circ} 20^{\prime} \mathrm{W}\right)$. The lake covers $282 \mathrm{~km}^{2}$ and is a dimictic, oligotrophic, tilt-block system. Marl substrates dominate the profundal region of the lake, where age-0 Bear Lake sculpin undergo diel vertical migrations. Juvenile Bear Lake sculpin in this region swim from the bottom ( $60 \mathrm{~m}$ maximum depth) to the ther-

\footnotetext{
${ }^{1}$ Present address: Missouri Department of Conservation, 2500 South Halliburton, Kirksville, Missouri 63501 , USA.
}

mocline at night, where they remain without feeding until daybreak. After returning to the bottom at dawn, they feed throughout the day on benthic invertebrates, mainly cyclopoid copepods and ostracods (Neverman 1989). Migration into the warmer water of the thermocline promotes digestion and growth (Wurtsbaugh and Neverman 1988).

\section{Methods}

We conducted feeding trials at different light intensities in a black, 40-L aquarium. Individual fish were placed in uncovered $250-\mathrm{mL}$ beakers inside this chamber. Water surrounding the beakers was kept at $10-11.5^{\circ} \mathrm{C}$. Light intensity in the chamber was varied by screening a $40-\mathrm{W}$ cool white fluorescent bulb with 2-46 layers of window screen (Blaxter 1968, 1969; Dabrowski and Jewson 1984). The bulb was suspended $200 \mathrm{~mm}$ above the surface of the water and extended the length of the aquarium. Light intensities were measured with a 400-700-nm, 2-pi sensor and a LiCor 188B radiometer. We could not measure light at intensities below $6.0 \times 10^{15}$ photos $\cdot \mathrm{m}^{-2} \cdot \mathrm{s}^{-1}$ (18 screens), but we estimated them by extrapolating the linear relationship $\left(r^{2}=0.999\right)$ between screen number $(S)$ and light intensity $(I): \log _{10} I=19.56-0.212 S$.

Feeding trials were conducted with fish that had been captured by nighttime trawling in the thermocline over the 30-50-m depth contour. These fish (mean total length, $20.7 \mathrm{~mm}$; SD, $2.8 \mathrm{~mm}$ ) were acclimated to laboratory conditions for at least $15 \mathrm{~d}$ and fed live zooplankton. We began experimental acclimatization by placing individual fish in $100 \mathrm{~mL}$ of filtered lake water in a 250 $\mathrm{mL}$ beaker and holding them in the dark for $12 \mathrm{~h}$ at $6^{\circ} \mathrm{C}$. We then held them an additional $2 \mathrm{~h}$ under experimental conditions of light and temperature.

We began each experiment by adding 30 live, late-instar copepods Epischura nevadensis to each of seven beakers while the light was briefly turned off. One control beaker without fish was used to estimate nonpredatory losses of the prey. Losses in the control beakers were negligible and were therefore disregarded in the calculation of predation rates. After prey were introduced, the light was turned on for a 20 -min feeding period. We 
stopped the experiment by turning out the lights and immediately removing the fish with the aid of a low-intensity red light. We then killed and counted the remaining prey and determined the number eaten by difference. Instantaneous feeding rate coefficients $(k)$ were calculated as

$$
k=\frac{-\log _{\mathrm{e}}\left(P_{f} / P_{i}\right)}{X \cdot t}
$$

$P_{f}=$ final number of prey in a beaker, $P_{i}=$ initial number of prey (30), $t=0.33 \mathrm{~h}$, and $X=$ number of predators (10) per liter (Dodson 1975). This coefficient indicates the number of liters cleared of prey by a single fish in $1 \mathrm{~h}$.

In all, 236 fish were tested at 15 light intensities ranging from complete darkness to the full intensity of the 40-W bulb diffused through two screens $\left(3.5 \times 10^{19}\right.$ photons $\left.\cdot \mathrm{m}^{-2} \cdot \mathrm{s}^{-1}\right)$. For comparison, full sunlight intensities measured with the 2-pi sensor are near $1 \times 10^{21}$ photons $\cdot \mathrm{m}^{-2} \cdot \mathrm{s}^{-1}$. Except for a single trial in August, experiments were conducted over a 3-week period in September and October 1985. During the first week we tested feeding at light intensities ranging from $10^{17}$ to $10^{19}$ photons $\cdot \mathrm{m}^{-2} \cdot \mathrm{s}^{-1}$ and in complete darkness. These trials were not randomized. When it became obvious that intermediate intensities would be necessary to describe the relationship between light and feeding, we randomly tested intensities between complete darkness and $10^{19}$ photons $\cdot \mathrm{m}^{-2}$. $\mathrm{s}^{-1}$. Analysis of covariance (ANCOVA) indicated no relationship between date of an experiment and feeding rates or between date and deviations from regressions of light and feeding rate, but it did indicate that fish length had a small but significant $(P<0.05)$ influence on feeding rates. We therefore used ANCOVA to correct the feeding rate coefficients to the mean size of Bear Lake sculpin used in the experiments.

To compare laboratory light intensities with those in the lake we determined a summer range of light extinction coefficients for Bear Lake. On seven dates (1 July, 18 July, 30 July, 14 August, 27 August, 16 September, and 25 October) in 1985 we measured intensities of photosynthetic active radiation (400-700 $\mathrm{nm}$ ) near midday at depths from 0 to $22 \mathrm{~m}$ with the LiCor radiometer. The vertical light extinction coefficients determined from these profiles were used to extrapolate intensities to the lake bottom under full sunlight and night sky conditions. The spectral composition and irradiance of full moon and starlight (Munz and McFarland 1977) were used to estimate light intensities in the water column at night.

\section{Results}

Light intensity had a pronounced effect on feeding rates of age-0 Bear Lake sculpin (Figure 1). The fish could feed in complete darkness, but at low rates. Feeding rates increased significantly $(F$ test; $\mathrm{df}=3,6 ; P<0.01$; Wilkinson 1988) as light intensities rose to approximately $6 \times 10^{15}$ photons $\cdot \mathrm{m}^{-2} \cdot \mathrm{s}^{-1}$. At intensities above $10^{17}$ photons. $\mathrm{m}^{-2} \cdot \mathrm{s}^{-1}$ feeding rates decreased significantly $(\mathrm{df}=$ 3,$2 ; P<0.005$ ) with increasing light. The variability in feeding rates was much greater at elevated light intensities than at lower levels (Figure 1).

For the $7 \mathrm{~d}$ they were calculated, vertical light extinction coefficients in Bear Lake were 0.22, 0.19, $0.22,0.24,0.22,0.28$ and $0.26 \cdot \mathrm{m}^{-1}$. Using these data we estimate that at depths of $40-60 \mathrm{~m}$ in the lake, where Bear Lake sculpin resided, daytime light intensities varied from $10^{14}$ to $10^{18}$ photons. $\mathrm{m}^{-2} \cdot \mathrm{s}^{-1}$ (Figure 1). At night, light intensities at this depth varied from $10^{8}$ to $10^{11}$ photons $\cdot \mathrm{m}^{-2} \cdot \mathrm{s}^{-1}$ depending primarily on moon phase.

\section{Discussion}

The rapid increase in their feeding rates with increases in light intensity up to intermediate levels shows that age-0 Bear Lake sculpin feed visually. Feeding rates of the fish increased rapidly in the range of light intensities found to be a common optima for many fishes $\left(10^{14}-10^{16}\right.$ photons $\mathrm{m}^{-2} \cdot \mathrm{s}^{-1} ; 0.01-1$ lux; Blaxter 1980$)$. Although young Bear Lake sculpin fed in complete darkness, feeding rates without light were only $10 \%$ of those at intermediate light intensities. We expect that adult Bear Lake sculpin also feed visually, because we have observed them under room lighting attempting to attack juvenile fish behind a wall of glass. This visual or diurnal feeding by both young and adult Bear Lake sculpin contrasts with the reported nonvisual or proprioceptive feeding by adult mottled sculpin and slimy sculpin $C$. cognatus (Hoekstra and Janssen 1985; Kraft and Kitchell 1986) and that of nocturnal feeding by prickly sculpin C. asper and slimy sculpin (Broadway and Moyle 1978; Brandt 1986).

We do not fully understand why young Bear Lake sculpin fed maximally at intermediate light intensities. We acknowledge that, due to differences in spectral quality between laboratory and lake and difficulties in obtaining natural backlighting in the laboratory, it is difficult to accurately extrapolate our laboratory feeding rates to lake conditions (Janssen 1981). Nevertheless, fish of the size we used in our experiments spend their 


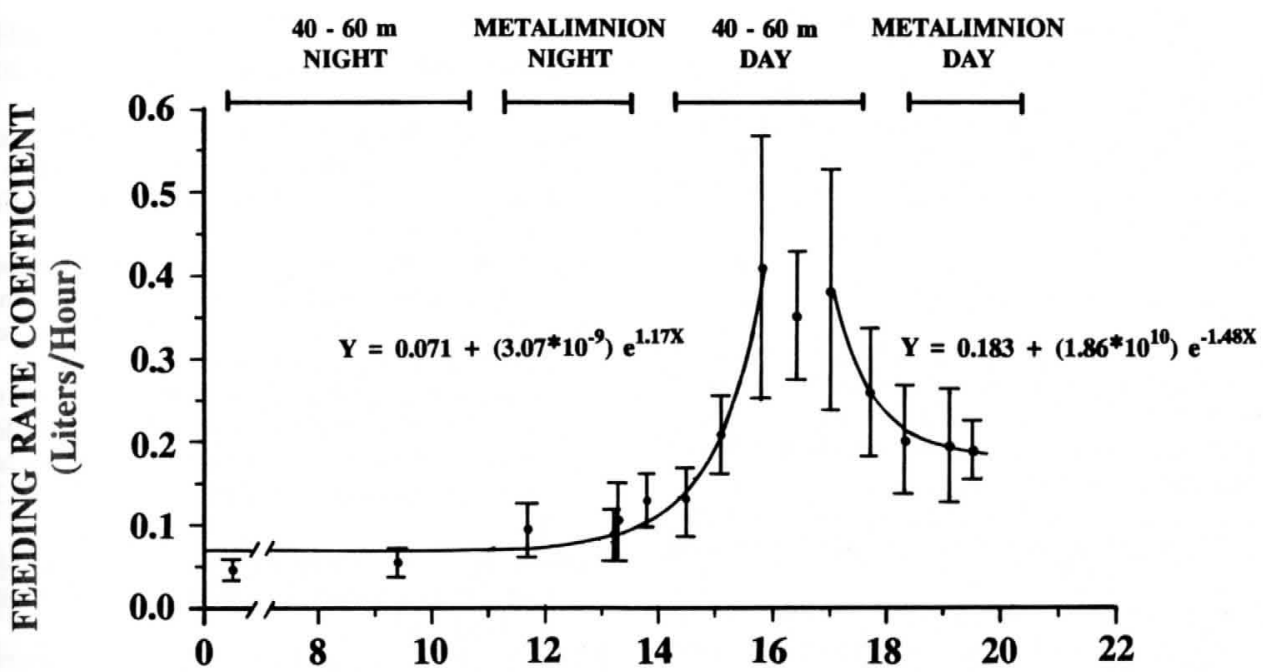

\section{IRRADIANCE [LOG(PHOTONS $\mathbf{M}^{-2}$ SEC $\left.^{-1}\right)$ ]}

FIGURE $1 .-$ Feeding rate coefficients ( $Y$, means $\pm 95 \%$ confidence intervals) of juvenile Bear Lake sculpin in relation to light intensity $(X)$. Each point represents the mean feeding rate of 6-29 fish. Least-squares asymptotic functions were fitted to the ascending and descending fields of points (Wilkinson 1988). The bars at the top of the figure indicate approximate light intensities through the day in different depth strata of Bear Lake. To convert light measurements to $\log _{10}\left(\mu \mathrm{E} \cdot \mathrm{m}^{-2} \cdot \mathrm{s}^{-1}\right)$, subtract 17.8 from the values given on the abscissa $(\mathrm{E}=$ einstein). To make an approximate conversion to $\log _{10}$ (lux), subtract 16.2 from each value.

days primarily at depths of $30-50 \mathrm{~m}$ in Bear Lake (Neverman 1989), where daytime light intensities correspond closely to the laboratory optimum for young Bear Lake sculpin (Figure 1). Conceivably, young Bear Lake sculpin have poorly developed photoprotective mechanisms, such as melanin shields (Munz 1971), to protect cone cells at high light intensities, which could inhibit feeding at high light intensities. Another possibility is that juvenile Bear Lake sculpin become inactive in bright light to avoid being preyed upon. Gregory (in press) found that juvenile chinook salmon Oncorhynchus tshawytscha fed less at low turbidities than at intermediate ones, and experimental results suggested that avoidance of bird predation was the reason. This hypothesis is also consistent with the behavior of sculpins in Lakes Ontario and Michigan, where fish in the littoral zone do not feed during daylight (Brandt 1986) but those in deeper water where light is low appear to feed continually (Kraft and Kitchell 1986). The increased variability in feeding rates at high light intensities in our experiment is also consistent with a behavioral shift that might affect some individuals but not others. The reduced variability in feeding rates at low light intensities is consistent with a physiological mechanism limiting visual acuity.

Ontogenetic shifts in the development and dis- tribution of sculpin might affect the relative importance of visual versus proprioceptive feeding. Larval and small juvenile Bear Lake sculpin feed during the day at moderate light intensities in the profundal zone but do not feed at night (Wurtsbaugh and Neverman 1988; Neverman 1989). Preliminary evidence suggests that by the time they reach $25 \mathrm{~mm}$ standard length, however, juvenile Bear Lake sculpin recruit to the littoral zone where light intensities are high (W. A. Wurtsbaugh, unpublished data). The feeding chronology of fish in the littoral zone is unknown. Adult Bear Lake sculpin are also found in the littoral zone, but the largest individuals are concentrated primarily in water deeper than $20 \mathrm{~m}$. A recent analysis of stomach fullness of adult Bear Lake sculpin collected at $40 \mathrm{~m}$ indicates that feeding is continual over $24 \mathrm{~h}$, suggesting that these fish can use proprioception to feed (D. Teuscher, Utah State University, and Wurtsbaugh, unpublished data). Williamson (1970) suggested, however, that adult Bear Lake sculpin in profundal areas feed primarily during the day. To fully understand the feeding mechanisms of these fish at different life stages will require additional field studies on their distribution and feeding chronology, and laboratory work on the importance of light and proprioception. 


\section{Acknowledgments}

This project was funded by the Ecology Center of Utah State University. We extend special thanks to C. Kraft, D. Beauchamp, R. Gregory, and M. Swift, who provided us with critical reviews of the manuscript.

\section{References}

Blaxter, J. H. S. 1966. The effect of light intensity on the feeding ecology of herring. Pages 393-409 in R. Bainbridge, G. C. Evans, and O. Rackham, editors. Light as an ecological factor. Blackwell Scientific Publications, Oxford, UK.

Blaxter, J. H. S. 1968. Visual thresholds and spectral sensitivity of herring larvae. Journal of Experimental Biology 48:39-53.

Blaxter, J. H. S. 1969. Visual thresholds and spectral sensitivity of flatfish larvae. Journal of Experimental Biology 51:221-230.

Blaxter, J. H. S. 1974. The role of light in the vertical migration of fish-a review. Pages 189-210 in G. C. Evans, R. Bainbridge, and O. Rackham, editors. Light as an ecological factor: II. Blackwell Scientific Publications, Oxford, UK.

Blaxter, J. H. S. 1980 . Vision and feeding of fishes. Pages 32-56 in J. E. Bardach, J. J. Magnuson, R. C. May, and J. M. Reinhart, editors. Fish behavior and its use in the capture and culture of fishes. International Center for Living Aquatic Resources Management, Manila.

Brandt, S. B. 1986. Ontogenetic shifts in habitat, diet, and diel-feeding periodicity of slimy sculpin in Lake Ontario. Transactions of the American Fisheries Society 115:711-715.

Broadway, J. E., and P. B. Moyle. 1978. Aspects of the ecology of the prickly sculpin, Cottus asper Richardson, a persistent native species in Clear Lake, Lake County, California. Environmental Biology of Fishes 3:337-343.

Dabrowski, K. R. 1982. The influence of light intensity on feeding of fish larvae and fry I. Coregonus pollan (Thompson) and Esox lucius (L). Zoologische Jahrbuecher. Abteilung für allgemeine Zoologie und Physiologie der Tiere 86:341-351.

Dabrowski, K. R., and D. H. Jewson. 1984. The influence of light environment on depth of visual feeding by larvae and fry of Coregonus pollan (Thompson) in Lough Neagh. Journal of Fish Biology 25:173-181.
Dodson, S. I. 1975. Predation rates of zooplankton in arctic ponds. Limnology and Oceanography 20:426433.

Emery, A. R. 1973. Preliminary comparisons of day and night habits of freshwater fish in Ontario lakes. Journal of the Fisheries Research Board of Canada 30:761-774.

Gregory, R. S. In press. Effects of turbidity on benthic foraging and predation risk in juvenile chinook salmon. Pages 62-71 in C. A. Simenstad, editor. Effects of dredging on anadromous Pacific Coast fishes. Washington Sea Grant Program, Seattle.

Hoekstra, D., and J. Janssen. 1985. Non-visual feeding behavior of the mottled sculpin Cottus bairdi in Lake Michigan. Environmental Biology of Fishes 12:111117.

Janssen, J. 1981. Searching for zooplankton just outside Snell's window. Limnology and Oceanography 26:1168-1171.

Jones, W. R., and J. Janssen. In press. Lateral line development and feeding behavior in the mottled sculpin, Cottus bairdi (Scorpaeniformes: Cottidae). Copeia.

Kraft, C. E., and J. F. Kitchell. 1986. Partitioning of food resources by sculpins in Lake Michigan. Environmental Biology of Fishes 16:309-316.

Munz, F. W. 1971. Vision: visual pigments. Pages 132 in W. S. Hoar and D. J. Randall, editors. Fish physiology, volume 5. Academic Press, New York.

Munz, F. W., and W. N. McFarland. 1977. Evolutionary adaptations of fishes to the photic environment. Pages 193-274 in F. Crescitelli, editor. The visual system in vertebrates. Springer-Verlag, New York.

Neverman, D. 1989. The diel vertical migration and feeding of underyearling Bear Lake sculpin Cottus extensus (Pisces, Cottidae). Master's thesis. Utah State University, Logan.

Wilkinson, L. 1988. SYSTAT: the system for statistics, version 4.0. SYSTAT, Evanston, Illinois.

Williamson, J. H. 1970. Stomach capacity, digestion rate, and 24-hour consumption rate for the Bear Lake sculpin (Cottus extensus). Master's thesis. Utah State University, Logan.

Wurtsbaugh, W. A., and D. Neverman. 1988. Postfeeding thermotaxis and daily vertical migration in a larval fish. Nature (London) 333:846-848.

Received February 6, 1991 Accepted October 7, 1991 